\title{
ASO Visual Abstract: Prognostic Performance of Alternative Lymph Node Classification Systems for Patients with Medullary Thyroid Cancer-A Single-Center Cohort Study
}

\author{
Dimitrios Prassas, MD ${ }^{1}$, Aristodemos Kounnamas, MD, MSc ${ }^{1}$, Kenko Cupisti, MD ${ }^{1,3}$, Matthias Schott, MD $^{2}$, \\ Wolfram Trudo Knoefel, MD, FACS ${ }^{1}$, and Andreas Krieg, MD $^{1}$ (i) \\ ${ }^{1}$ Department of Surgery (A), Heinrich-Heine-University and University Hospital Duesseldorf, Duesseldorf, Germany; \\ ${ }^{2}$ Division for Specific Endocrinology, Heinrich-Heine-University and University Hospital Duesseldorf, Duesseldorf, \\ Germany; ${ }^{3}$ Present address: Department of Surgery, Marien-Hospital Euskirchen, Euskirchen, Germany
}

Various LNR and LODDS classifications were verified in patients with MTC. Two alternative lymph node classification systems demonstrated prognostic superiority over the $\mathrm{N}$ category in MTC patients regarding OS, but did not outperform the latter in terms of discriminative ability (https://doi.org/10.1245/s10434-021-11134-3).

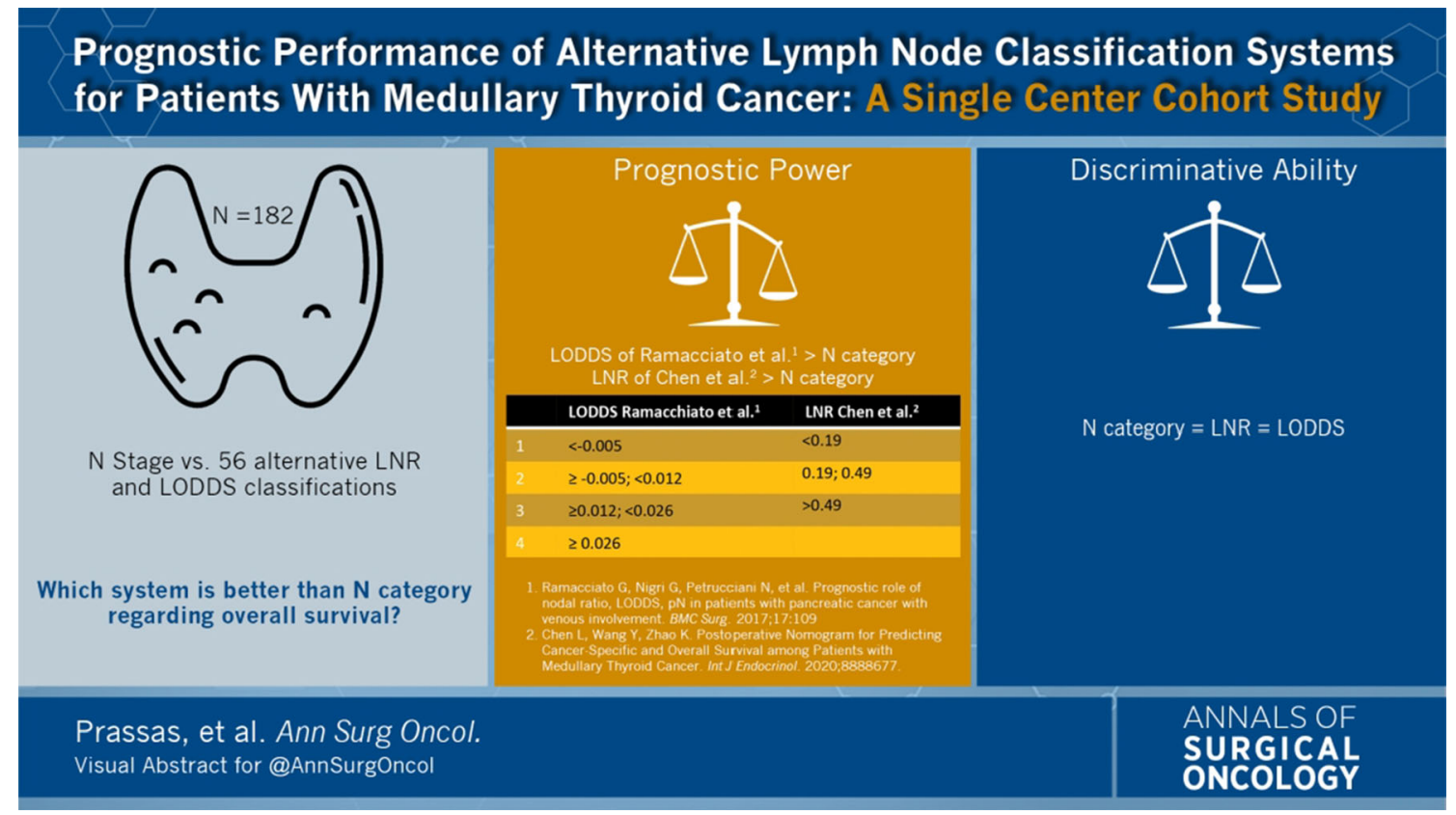

(C) Society of Surgical Oncology 2022

W. T. Knoefel, MD, FACS

e-mail: knoefel@med.uni-duesseldorf.de

A. Krieg, MD

e-mail: andreas.krieg@med.uni-duesseldorf.de
FUNDING No external funding was received for this study

DISCLOSURE There are no conflicts of interest.

Publisher's Note Springer Nature remains neutral with regard to jurisdictional claims in published maps and institutional affiliations. 